\title{
DEKLINA ZGODBA? \\ ZGODBE MIGRANTK, KI NISO OBSTALE PRED ZIDOVI
}

Jernej MLEKUŽ

\section{PRED ZIDOM}

Deklina zgodba je, kot večina bralk in bralcev dobro ve, distopični roman Margaret Eleanor Atwood (2017; večini bolj znan kot TV-serija). Glavna junakinja, dekla Odfreda, ki živi pri poveljniku in njegovi ženi, se sme enkrat dnevno sprehoditi do trgovin s slikami na izveskih namesto napisov; ženske ne smejo več brati. Enkrat mesečno mora leči na hrbet in upati, da jo bo poveljnik oplodil, v času upada rodnosti so dekle cenjene le, če rojevajo. Čeprav je bil svet, v katerem so živele junakinje pričujočega sklopa, drugačen od distopičnega sveta dekle Odfrede, pa vse naše junakinje povezuje nekaj skupnega. V romanu se dekla večkrat ustavi pred zidom. Junakinje tega sklopa počnejo nekaj podobnega - stojijo pred zidovi. In prav tako kot dekle Odfrede tudi glavnih junakinj pričujočega sklopa zidovi ne ustavijo.

\section{ONKRAJ ZIDU}

Zgodbe migrantk, ki spregovorijo v pričujočem sklopu, govorijo o družbah, kulturah, skupnostih, ki so jim migrantke pripadale. A govorijo tudi o tem, kako so v teh družbah, kulturah, skupnostih izstopale. Bile so, kot lahko beremo v objavljenih člankih, zavedne pripadnice svoje narodne skupnosti, a so hkrati s svojim delom tudi presegale nacionalne okvire in z zanimanjem in naklonjenostjo spoznavale, odkrivale in raziskovale nove nacionalne, nadnacionalne in druge prostore. Bile so precej drugačne od večine vrstnic. Niso živele vlog mater, gospodinj, kraljic doma, temveč predvsem vloge antropologinj oziroma raziskovalk staroselskih ljudstev (dr. Branislava Sušnik), slikark (Bara Remec) in misijonark ter pisateljic (Marija Sreš). Tudi kot antropologinje, slikarke, misijonarke in pisateljice niso bile »tipične« (karkoli že ta sumljivi pridevnik pomeni) predstavnice svoje poklicne vrste, temveč so bile, kot boste brali, »drugačne« antropologinje, slikarke, misijonarke in pisateljice svojega časa. Z razkrivanjem odstopanj naših junakinj bi lahko še nadaljeval, a to boste, bralke in bralci, $v$ prispevkih brali sami.

Dr. znanosti, znanstveni sodelavec, Inštitut za slovensko izseljenstvo in migracije ZRC SAZU, Novi trg 2, SI-1000 Ljubljana; mlekuz@zrc-sazu.si, https://orcid.org/0000-0001-6918-1194 
Sklop, ki je pred vami, obeležuje 100-letnico rojstva dr. Branislave Sušnik. Nastal je v ciljnoraziskovalnem projektu »Dr. Branislava Sušnik in sodobniki - ambasadorji slovenske znanosti v Južni Ameriki« (ARRS, V6-1925) in raziskovalnem programu »Narodna in kulturna identiteta slovenskega izseljenstva $v$ kontekstu raziskovanja migracij« (ARRS, P5-0070). Prispevkoma o življenju in delu slovenske antropologinje v Paragvaju smo dodali še zgodbi v Argentini živeče slikarke Bare Remec in misijonarke ter pisateljice Marije Sreš, ki je velik del življenja preživela v Indiji. Enkratne zgodbe žensk so tako v skupni družbi zasijale v novih oblačilih.

Raziskovanje ženk, tudi migrantk, ki so s svojima delom in delovanjem izstopile iz anonimnih zgodovinskih množic, jih pa ne moremo strpati v problematično kategorijo "velikih ljudi«, ki so se odlikovali pri ustvarjanju politično relevantne zgodovine, ni novo.' Če se omejimo samo na slovenski prostor in le na nekatere ženske, ki so bile vsaj del svoje življenjske poti tudi migrantke: pisateljica Zofka Kveder (Poniž Mihurko 2003; Tucovič 2006), radijska voditeljica in ena vidnejših osebnosti slovenske skupnosti v Avstraliji Mariza Ličan (Čebulj Sajko 2005), publicistka in društvena voditeljica ter organizatorka med Slovenci in Slovenkami v ZDA, Marie Prisland (Milharčič Hladnik 2007), slikarka Ivana Kobilica (Strle 2018) in še katera. Odkrivanje pomembnih žensk, ki so s svojima delovanjem in življenjem rušile ali vsaj rahljale trdnost velikih zgodb (na udaru je bila predvsem patrilinerna zgodba), lahko razumemo kot nekakšno nadaljevanje ženskega emancipacijskega projekta, ki ženske vpisuje v zgodovino in splošno vednost (glej Verginella 2004b: 8). To razkrivanje izstopajočih žensk je lahko več kot le emancipacijski projekt. Je tudi spoznavni, epistemološki projekt.

Po Perryju Andersonu (2012) nam pri raziskovanju zgodovine več kot pravila povedo anomalije. Anomalije namreč govorijo tudi o pravilih, medtem ko pravila govorijo le sama zase. Ali, z drugimi besedami, ženske, ki so prestopale zidove, ne govorijo le o svetu na tej strani zidu, temveč tudi o svetu onkraj zidov.

1 Čeprav že od antike sledimo ženskim prikazom preteklosti, jim vse do 20. stoletja ni uspelo postati del obče zgodovine. V 20. stoletju so ženske začele počasi vstopati v zgodovino kot pomembne vladarice, plemkinje, redovnice, slikarke idr. Do zgodovinskega vpisa manj vidnih žensk, na primer kmetic in delavk, je prišlo v šestdesetih in sedemdesetih letih 20. stoletja, ko se je pod vplivom marksističnega zgodovinopisja povečalo zanimanje za zgodovino nižjih razredov. (Verginella 2004a: 8) 


\section{LITERATURA}

Anderson, Perry (2012). The Force of the Anomaly. London Review of Books 8, 3-13.

Atwood, Margaret Eleanor (2017). Deklina zgodba. Ljubljana: Mladinska knjiga.

Čebulj Sajko, Breda (2005). Mariza Ličan: Sledi življenja izseljenke. Dve domovini / Two Homelands 21, 143-162.

Milharčič Hladnik, Mirjam (2007). Marie Prisland - her Role in Preserving Slovenian Culture and Tradition Among Slovenian Migrants in the United States. Dve domovini / Two Homelands 25, 229-248.

Poniž Mihurko, Katja (2003). Drzno drugačna: Zofka Kveder in podobe ženskosti. Ljubljana: Delta.

Strle, Urška (2018). V preseku mobilnosti in socialnih mrež: Biografska skica Ivane Kobilca. Dve domovini / Two Homelands 48, 147-163.

Tucovič, Vladka (2006). Zagreb, Ljubljana, Praga: Korespondenca Zofke Kveder in njene hčere Vladimire Jelovšek. Dve domovini / Two Homelands 23, 77-99.

Verginella, Marta (2004a). Suha pašta, pesek in bombe: Vojni dnevnik Bruna Trampuža. Koper: Univerza na Primorskem, Znanstvenoraziskovalno središče.

Verginella, Marta (2004b). Zgodovina žensk ali ženska zgodovina? Ženske skozi zgodovino: Zbornik referatov 32. zborovanja slovenskih zgodovinarjev. Celje, 30. september-2. oktober 2004. Ljubljana: Zveza zgodovinskih društev Slovenije, 7-11. 